Almirall, J Fortea Shareholder with: Almirall, Employee of: Almirall, M Falques Employee of: Almirall, S Shiff Employee of: Forest Research Institute, K Shi Employee of: Forest Research Institute, H A Schneier Employee of: Forest Research Institute, J M Johnston Employee of: Ironwood Pharmaceuticals.

\section{PTU-153 CAN A 10 YEAR FRACTURE RISK SCORE (FRAX) BE USED TO AVOID DUAL ENERGY X-RAY ABSORPTIOMETRY (DEXA) SCANS IN PATIENTS WITH COELIAC DISEASE?}

doi:10.1136/gutjnl-2012-302514c.153

E Derbyshire, ${ }^{*}$ A Dhar. Gastroenterology, County Durham \& Darlington NHS Foundation Trust, Bishop Auckland, UK

Introduction The BSG Guidelines for Osteoporosis in Inflammatory Bowel Disease and Coeliac state there is a definite increased risk of fracture in these conditions and recommend DEXA scanning after introduction of gluten free diet in subgroups of patients where the risk of osteoporotic fracture is high. A 10-year risk of major osteoporotic and hip fracture using the WHO Fracture Risk Assessment Score (FRAX) can be calculated in patients with coeliac disease and this score mapped to the National Osteoporosis Guideline Group (NOGG) assessment tool may be better to decide the need for a DEXA scan.

Methods The aim of this study was to determine if the WHO FRAX can be used to screen patients with Coeliac disease to decide who needed a DEXA scan, and make pathways more cost effective. A retrospective analysis of all duodenal biopsies in our Trust between June 2010 and April 2011 was undertaken and 50 definitive pathological diagnoses of coeliac disease that is, Marsh stage 1 to 4 were identified. The notes of these patients were reviewed to see if a DEXA scan had been requested and to calculate their FRAX score with and without a BMD measurement.

Results Of 50 patients with a definitive pathological diagnosis of coeliac disease, 33 were female and 17 male. The median age at diagnosis was 45 , with $30(60 \%)$ of patients aged between 42 and 71 yrs, making them eligible for the FRAX score. Documentation of smoking status, alcohol history, use of corticosteroids, past medical history and family history of fracture was done for most patients. Of the 30 patients, 13 had already had a DEXA scan; in two pts a FRAX score was unable to be calculated due to information not being documented. 17 had not had a DEXA scan; seven of these were unable to be FRAX scored due to information not being documented. 11 patients had both FRAX scores and DEXA scores: 4 had T scores $<-2.5$, indicating eligibility for treatment of osteoporosis. In these patients FRAX scores, without a BMD measurement, ranged from $6.1 \%$ to $13 \%$ for a major osteoporotic fracture and $0.9 \%$ to $6.6 \%$ for a hip fracture. In the seven patients with T scores $>-2.5$, FRAX scores, without a BMD measurement, ranged from $3.1 \%>$ $9.5 \%$ for a major osteoporotic fracture and $0.2 \%>1.8 \%$ for a hip fracture.

Conclusion The majority of coeliac patients in this study were females, over the age of 40 . Coeliac patients, over the age of 40 , with FRAX scores for a major osteoporotic fracture $>9.5 \%$ and for a hip fracture $>1.8 \%$ may need DEXA scans and be offered osteoporosis treatment. A cost effectiveness analysis of this strategy is needed to change the current guidance.

Competing interests E Derbyshire: None Declared, A Dhar Speaker bureau with: Several Pharmaceutical Companies, Conflict with: Honoraria from Pharmaceutical and endoscopy industry.

\section{REFERENCES}

1. http://www.shef.ac.uk/FRAX

2. Scott EM, Gaywood I, Scott BB, et al. BSG Guidelines for Osteoporosis in Coeliac Disease and Inflammatory Bowel Disease. 2000.

\section{PTU-154 INVESTIGATION OF THE OPTIMAL DURATION OF THE GLUCOSE HYDROGEN METHANE BREATH TEST}

doi:10.1136/gutjnl-2012-302514c.154

${ }^{1,2} \mathrm{E}$ Grace, ${ }^{*}{ }^{3} \mathrm{~K}$ Thomas, ${ }^{3} \mathrm{~S}$ Gupta, ${ }^{2} \mathrm{~A}$ Lalji, ${ }^{1} \mathrm{~K}$ Whelan, ${ }^{4} \mathrm{C}$ Shaw, ${ }^{2} \mathrm{~J}$ Andreyev ${ }^{1}$ Nutritional Sciences, King's College London, London, UK; ${ }^{2} \mathrm{GI}$ Unit, London, UK; ${ }^{3}$ Research Data Management \& Statistics Unit, London, UK; ${ }^{4}$ Dietetics Department, The Royal Marsden NHS Foundation Trust, London, UK

Introduction Historically, the glucose hydrogen breath test has been popular for diagnosing small intestinal bacterial overgrowth (SIBO). Lately the glucose hydrogen methane breath test has become available. It is non-invasive and simple to carry out. This test is used as a part of standard clinical practice in patients suspected of having SIBO in our hospital. There are limited published data on the optimal test duration, with $3 \mathrm{~h}$ being the longest reported. This study aimed to determine if there is a significant difference in the number of patients who would be considered positive for SIBO depending on test duration.

Methods Patients in whom the gastroenterologist suspected SIBO underwent a breath test performed by endoscopy nurses using the QuinTron BreathTracker DP Digitial Microlyzer that measures hydrogen $\left(\mathrm{H}_{2}\right)$ and methane $\left(\mathrm{CH}_{4}\right)$ concentrations in parts per million (ppm). Pre-test preparation included avoiding slowly absorbed carbohydrates, fibre and large meals and limiting dairy intake and carbonated drinks for $24 \mathrm{~h}$, a $12 \mathrm{~h}$ fast and avoiding exercise and cigarette smoking for $2 \mathrm{~h}$. Breath $\mathrm{H}_{2}$ and $\mathrm{CH}_{4}$ concentrations were noted at baseline. Subjects then consumed $75 \mathrm{~g}$ (or $50 \mathrm{~g}$ if weight was $<50 \mathrm{~kg}$ ) in $100 \mathrm{ml}$ of water. Thereafter, breath $\mathrm{H}_{2}$ and $\mathrm{CH}_{4}$ values were recorded every $20 \mathrm{~min}$ for $3 \mathrm{~h}$ (or less if positive). Positive test was defined as fasting $\mathrm{H}_{2} \geq 20$ or $\mathrm{CH}_{4} \geq 10 \mathrm{ppm}$ or a rise in $\mathrm{H}_{2} \geq 12$ or $\mathrm{CH}_{4} \geq 6 \mathrm{ppm}$

Results 98 males and 95 females, median age 63 years (range 28-86) underwent a breath test. Of these, $67(35 \%)$ had a positive result for one or both gases: $18(32 \%)$ at baseline, $39(60 \%)$ by $40 \mathrm{~min}, 56$ (84\%) by $100 \mathrm{~min}, 60$ (90\%) by $140 \mathrm{~min}, 67$ (100\%) by $160 \mathrm{~min} .126$ patients had negative breath tests; $n=75$ had the test performed for a full $3 \mathrm{~h}, 26(20 \%)$ had the test performed for 100 min only. In patients where the test was performed for $3 \mathrm{~h}$ the $95 \%$ CI for a false negative result at $100 \mathrm{~min}$ is 0.003 to 0.10 .

Conclusion Most patients with SIBO will have a positive result by $100 \mathrm{~min}$. This suggests that a reduction in the duration of the test can be achieved without compromising the number of true positives being diagnosed with SIBO.

Competing interests None declared.

\section{PTU-155 IS THE GLUCOSE HYDROGEN METHANE BREATH TEST AN ACCURATE DIAGNOSTIC TOOL FOR SMALL INTESTINAL BACTERIAL OVERGROWTH?}

doi:10.1136/gutjnl-2012-302514c.155

${ }^{1} \mathrm{R}$ I Rusu, ${ }^{1,2} \mathrm{E}$ Grace, ${ }^{*}{ }^{3} \mathrm{~K}$ Thomas, ${ }^{2} \mathrm{~K}$ Whelan, ${ }^{4} \mathrm{C}$ Shaw, ${ }^{1} \mathrm{H} \mathrm{J}$ N Andreyev. ${ }^{1}$ The GI Unit, Royal Marsden NHS Foundation Trust, London, UK; ${ }^{2}$ Diabetes and Nutritional Sciences Division, King's College London, London, UK; ${ }^{3}$ Department of Computing, Royal Marsden NHS Foundation Trust, London, UK; ${ }^{4}$ Department of Dietetics, Royal Marsden NHS Foundation Trust, London, UK

Introduction Small intestinal bacterial overgrowth (SIBO) is probably the most common cause for chronic gastrointestinal (GI) symptoms following cancer treatments. There is no diagnostic gold standard. We assessed whether the glucose hydrogen methane breath test has greater value than the hydrogen breath test alone and whether a duodenal (D2) aspirate improves the diagnostic yield. Methods Patients in a cancer centre referred for potential SIBO Breath hydrogen $(\mathrm{H} 2)$ and methane $(\mathrm{CH} 4)$ were measured in parts/ 